\title{
Vascular Responsiveness and Eicosanoid Production in Diabetic Rats
}

\author{
D. M. Roth, D. K. Reibel and A. M.Lefer \\ Department of Physiology, Jefferson Medical College, Thomas Jefferson University, Philadelphia, Pennsylvania, USA
}

\begin{abstract}
Summary. Vascular responsiveness to vasoactive eicosanoids as well as vascular prostacyclin and thromboxane production was investigated in 7-10 weeks alloxan-diabetic rats. Aortic rings from diabetic rats exhibited increased responsiveness to carbocyclic thromboxane $\mathrm{A}_{2}$, a thromboxane analogue, when compared to control rat aortae. Isolated perfused hearts of diabetic rats showed increased vascular responsiveness to 9,11-methanoepoxy $\mathrm{PGH}_{2}$ (U-46619), an endoperoxide analogue. Diabetes resulted in a reduction in prostacyclin generation by isolated incubated aortae which was overcome by the addition of arachidonic acid but not by homogenization of incubated aortic tissue. In contrast, prostacyclin, but not thromboxane, generation was elevated in isolated perfused hearts of
\end{abstract}

diabetic animals in response to moderate doses of arachidonic acid, but at high doses of arachidonate, more thromboxane was formed by perfused hearts of diabetic rats. These results suggest that different vessels can either increase or decrease their prostaglandin production in response to diabetes. The alterations in prostanoid production may be due to differential changes in prostacyclin and thromboxane synthesis in vessels which, in turn, may be related to the changes in vascular responsiveness.

Key words: Vascular reactivity, arachidonic acid, prostacyclin, carbocyclic thromboxane $A_{2}$, thromboxane $A_{2}$, isolated perfused hearts.
Vascular integrity is profoundly altered in diabetic animals during the progression of diabetes. Some of these changes may be related to the ability of the blood vessel wall to synthesize and release vasoactive prostanoids [11]. In this regard, vascular tissue from diabetic animals was shown to produce less of the vasodilator prostanoid, prostacyclin $\left(\mathrm{PGI}_{2}\right)[1,17,21]$, a substance that also prevents platelet aggregation [4] and stabilizes lysosomal membranes [9]. Others have reported, however, an enhanced generation of $\mathrm{PGI}_{2}$ by the coronary vasculature of diabetic rats [18]. Very little is known about the ability of vessels from diabetic animals to generate thromboxane $\mathrm{A}_{2}\left(\mathrm{Tx}_{2}\right)$, a potent vasoconstrictor, inducer of platelet aggregation and labilizer of lysosomal membranes [5]. Thromboxane $A_{2}$ is produced largely by platelets [19], but also is generated by blood vessels and myocardial cells [7]. In this regard, platelets from diabetic patients produce more $\mathrm{TxA}_{2}$ than those from normal subjects $[4,8]$.

Another important aspect of altered vascular homeostasis in diabetes is responsiveness to endogenous vasoactive humoral substances. In this regard, blood vessels of diabetic animals are reported to be hyperresponsive to vasoconstrictor prostanoids and hypo- responsive to vasodilator prostanoids [13, 23]. Whether any relationship exists between the ability of the blood vessel to generate vasoactive prostanoids and its vasoactive sensitivity to these agents (e.g. $\mathrm{PGI}_{2}$ and $\mathrm{TxA}_{2}$ ) remains to be determined.

The major purposes of this study were (a) to define the ability of large arteries (e.g. aorta) and of the coronary vasculature of diabetic animals to generate $\mathrm{PGI}_{2}$ and $\mathrm{TxA}_{2}$, and (b) to relate these findings to the responsiveness of arterial vessels to $\mathrm{PGI}_{2}$ and to chemically stable endoperoxide and thromboxane analogues.

\section{Methods \\ Induction of Diabetes}

Diabetes was induced in male Sprague-Dawley rats (weight 225$250 \mathrm{~g}$ ) by intravenous injection of alloxan at a dose of $45 \mathrm{mg} / \mathrm{kg}$ body weight. Diabetic animals were used 7-10 weeks later. Weightmatched non-diabetic animals were used as controls. Before sacrifice, glucosuria was confirmed in diabetic rats with Ketodiastix (Miles Laboratory, Elkhart, Indiana, USA). Blood collected at the time of experimentation was used for serum glucose determinations by a glucose oxidase method [16]. Serum glucose averaged $8.9 \pm 0.3$ and $25.1 \pm 1.0 \mathrm{mmol} / \mathrm{l}$ (mean $\pm \mathrm{SEM}$ ) for control and diabetic rats, respectively. 


\section{Cardiac Perfusion}

Hearts were quickly excised and abdominal and thoracic aortae removed from pentobarbital-anaesthetized rats. All hearts were perfused by the Langendorff procedure for an initial $10 \mathrm{~min}$ at an aortic pressure of $60 \mathrm{mmHg}$. Hearts were then perfused retrogradely through the aorta at a constant flow of $14-16 \mathrm{ml} / \mathrm{min}$ while they were electrically paced at a rate of 300 beats $/ \mathrm{min}$. The perfusate employed was Krebs-Henseleit bicarbonate solution containing $11 \mathrm{mmol} / 1 \mathrm{glu}-$ cose at $\mathrm{pH} 7.35$, and maintained at $37 \pm 0.2^{\circ} \mathrm{C}$ equilibrated with $95 \%$ $\mathrm{O}_{2}+5 \% \mathrm{CO}_{2}$. The perfusate was not recirculated at any time. Coronary perfusion pressure was monitored continuously throughout all experiments from a side-arm in the aortic inflow tract, connected to a Statham P-23 pressure transducer (Statham Medical Instruments, Hato Rey, Puerto Rico) and recorded on a Grass Model 7 oscillographic recorder (Grass Instruments, Quincy, Massachusetts, USA).

\section{Vascular Responsiveness}

Thoracic aortae were trimmed of excess fat and connective tissue and cut into rings approximately $4 \mathrm{~mm}$ in length. The rings were suspended from a Statham FT-03 force transducer (Statham Medical Instruments) and secured using two stainless steel hooks and silk. The rings were suspended in $20 \mathrm{ml}$ water jacketed baths containing oxygenated Krebs-Henseleit solution maintained at $37 \pm 0.2^{\circ} \mathrm{C}$. Rings were preloaded with $1 \mathrm{~g}$ force and allowed to equilibrate for $2 \mathrm{~h}$ before adding any humoral agent. The Krebs-Henseleit solution was changed every 20-30 min during the incubation. Following the experiment, the cross-sectional area of the rings was measured, and the tissue was then dried for $24 \mathrm{~h}$ in order to obtain dry weight values.

\section{Eicosanoid Measurements}

Segments of abdominal aortae were preincubated in Krebs-Henseleit buffer $(1 \mathrm{ml})$ at $20^{\circ} \mathrm{C}$ for $2 \mathrm{~h}$ to remove substances formed during the removal of the vessel. The vessels were then weighed, placed in Krebs-Henseleit buffer $(0.1 \mathrm{ml} / 1 \mathrm{mg}$ tissue $)$ and incubated in a metabolic shaker bath at $37^{\circ} \mathrm{C}$ for $10 \mathrm{~min}$. Aliquots $(250 \mu \mathrm{l})$ of buffer were sampled at $0,2.5,5,7.5$ and $10 \mathrm{~min}$. Arachidonic acid $(80 \mathrm{umol} / \mathrm{l})$ in $1 \mathrm{mmol} / \mathrm{l}$ sodium bicarbonate was added to some vessels for a 10 -min incubation period. Following incubation, some vessels were suspended in Krebs-Henseleit solution $(0.2 \mathrm{ml} / \mathrm{mg}$ tissue) and homogenized using a Brinkman Polytron homogenizer (New York, USA) at a setting of 10 for two 10 -s bursts. After homogenization, aliquots $(250 \mu \mathrm{l})$ of the homogenate were removed for 6-keto-PGF $\mathrm{P}_{1 \alpha}$ analysis. The concentration of 6-keto-PGF ${ }_{1 \alpha}$ (i. e. the stable breakdown product of prostacyclin) was determined in vessel homogenates and incubation buffers, as well as in coronary effluents using a specific radioimmunoassay according to previously established methods [7]. $\mathrm{TxB}_{2}$, the stable breakdown product of $\mathrm{TxA}_{2}$, was also measured in coronary effluents using a specific radioimmunoassay according to the method of Lewy et al. [10].

Statistical evaluations of the data were performed using Student's t-test for unpaired comparisons.

\section{Results}

Body and heart weights of diabetic and weight-matched control rats were recorded and analyzed. No significant differences were observed in heart weights of diabetic animals when compared with weight-matched controls, nor were there any changes in dry weight to wet weight ratios of hearts from control or diabetic rats. In preliminary studies, no significant differences were observed between age-matched and weight-matched control animals.

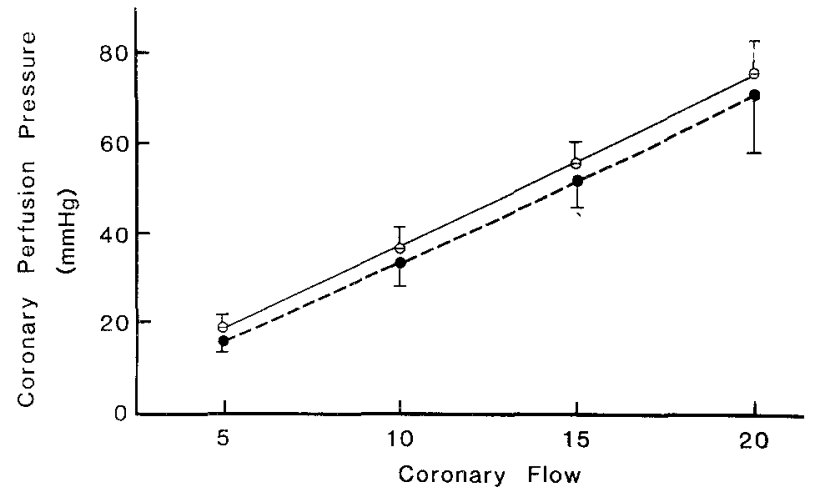

$(\mathrm{ml} / \mathrm{min})$

Fig. 1. Coronary perfusion pressure-flow relationship. Hearts of diabetic animals (---- ) and weight-matched controls $\left(\mathrm{O}_{-} \mathrm{O}\right)$ were perfused at a constant flow rate. Coronary flow was increased at 5min intervals by means of a variable speed pump. Coronary perfusion pressure was measured by means of a side-arm in the aortic inflow tract. Values represent mean \pm SEM for six hearts in each group

\section{Vascular Reactivity}

Vascular reactivity of diabetic rat aortic smooth muscle exhibited an increased sensitivity to thromboxane-like substances. There was a significantly increased constrictor response to the $\mathrm{TxA}_{2}$ analogue, carbocyclic $\mathrm{TxA}_{2}$ at $100 \mathrm{nmol} / 1(p<0.05)$ in aortic rings isolated from diabetic rats. The amount of force generated in diabetic vessels was $1060 \pm 187 \mathrm{mg}$ compared with $603 \pm 74 \mathrm{mg}$ force for control aortic rings $(p<0.05)$. This same trend of increased constrictor responsiveness was observed also with the endoperoxide analogue (U-46619) at 100 $\mathrm{nmol} / \mathrm{l}$, although it was not statistically significant. The same differences were observed even after normalization of values using the cross sectional area or tissue dry weight; however, prostacyclin at 50 and $100 \mathrm{nmol} / 1$ failed to dilate the aortic ring preparation in vessels from either control or diabetic rats. The calcium channel blocker, nifedipine $(50 \mathrm{ng} / \mathrm{ml}$, Pfizer Laboratories, New York, USA) was able to relax completely (i.e. $95 \%-100 \%$ ) the preparation in the presence of $100 \mathrm{nmol} / \mathrm{l}$ carbocyclic thromboxane $\mathrm{A}_{2}$.

Vascular responsiveness was studied also in the coronary circulation of diabetic and control rats. Before studying the effect of diabetes on vascular responsiveness to prostaglandin analogues in isolated perfused hearts, however, it was necessary to determine whether diabetes altered the passive resistance of the coronary vasculature. Therefore, the relationship between coronary flow and coronary perfusion pressure was studied in isolated perfused hearts of both control and diabetic animals. Figure 1 shows that changes in coronary flow were associated with changes in coronary perfusion pressure of a comparable magnitude in hearts from control and diabetic rats. Thus, no measurable alteration in the passive resistance of the coronary vasculature occurred 7-10 weeks after the induction of diabetes. 


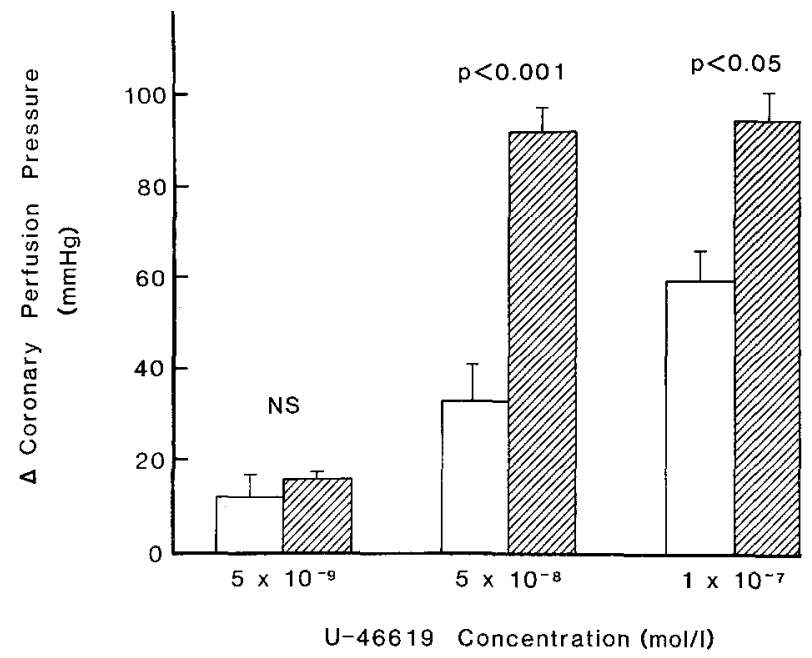

Fig. 2. The effect of diabetes on coronary vascular responsiveness to the endoperoxide analogue, U-46619. Hearts of diabetic and weight-matched control $\square$ animals were perfused at a constant flow of $14-16 \mathrm{ml} / \mathrm{min}$ with Krebs-Henseleit solution. Following a $15-\mathrm{min}$ equilibration period, hearts were perfused for $10 \mathrm{~min}$ with KrebsHenseleit buffer containing U-46619 at the concentrations indicated. Perfusion with each dose of U-46619 was followed by a 15 min washout perfusion. Values represent the mean \pm SEM for six hearts in each group

Hence, the change in the vascular responsiveness to U-46619 found in hearts of diabetic animals (Fig. 2) is even more striking. Vessels of control and diabetic hearts responded to the same threshold dose of U46619. However, at higher doses of U-46619, diabetic vessels exhibited up to twice the constrictor response of the controls. Moreover, diabetic hearts tended to develop arrhythmias when perfusion pressure exceeded $160 \mathrm{mmHg}$. Approximately 50\% of these hearts subsequently went into a contracture state associated with a very rapid and large increase in perfusion pressure. Therefore, the vascular response to U-46619 reported in these hearts was based on coronary perfusion pressure prior to contracture. The contracture and elevated perfusion pressure could be reversed by nifedipine $(100 \mathrm{ng} / \mathrm{ml})$.

The increased responsiveness of the vasculature of diabetic hearts to U-46619 did not appear to be due to a non-specific increase in responsiveness to constrictor agents, since increased reactivity to $10^{-5} \mathrm{~mol} / 1$ serotonin was not observed (perfusion pressure of $25 \pm 4$ and $30 \pm 4 \mathrm{mmHg}$ for hearts from control and diabetic rats, respectively) under the same experimental conditions.

\section{Eicosanoid Generation}

Prostacyclin generation was originally studied in both the abdominal and thoracic aorta where a significant decrease in prostacyclin production was observed in both thoracic and abdominal aortas from diabetic rats $(p<0.01)$. Subsequent studies were carried out using the

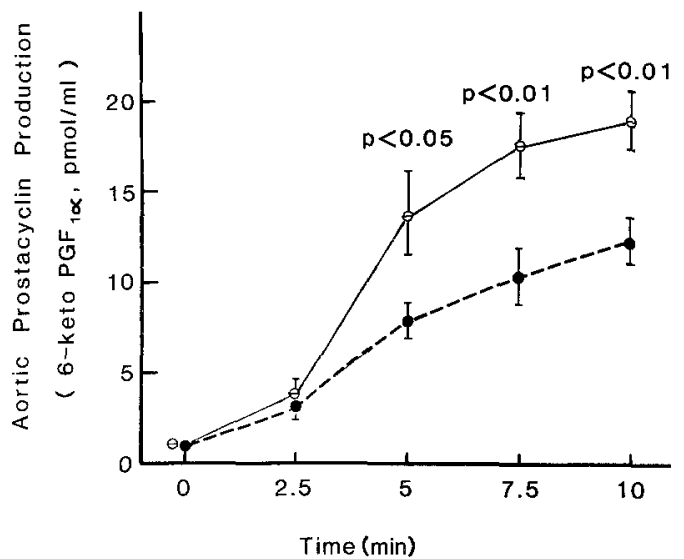

Fig. 3. Time course of prostacyclin release by abdominal aortae from diabetic (---- ) and control rats $(\mathrm{O}-\mathrm{O})$. Values represent mean \pm SEM of ten rats

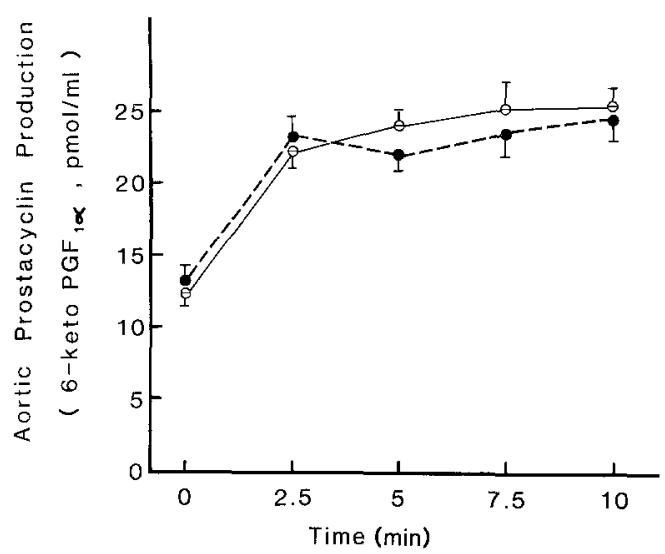

Fig.4. Prostacyclin release by abdominal aortae from diabetic (---) and control rats $\left(\mathrm{O}_{-} \mathrm{O}\right)$ following addition of arachidonic acid $(80 \mu \mathrm{mol} / 1)$ at time 0 . Values represent mean \pm SEM for four paits of vessels

abdominal aorta since this proved to have a more consistent response. Prostacyclin generation over a $7.5 \mathrm{~min}$ incubation period was significantly reduced in the abdominal aorta of the diabetic rat. Figure 3 displays the time course of this prostacyclin generation. Thus, a significantly reduced prostacyclin generation occurred at $5 \mathrm{~min}$, with maximal decreases at 7.5 and $10 \mathrm{~min}$. The reduction in prostacyclin generation could be abolished by addition of arachidonic acid $(80 \mu \mathrm{mol} / \mathrm{l})$ to the incubation medium. Figure 4 shows that arachidonic acid actually elevated the reduced $\mathrm{PGI}_{2}$ values in diabetic vessels, suggesting a substrate limiting factor during diabetes. In this regard, homogenates of the abdominal aortae from diabetic rats also showed a significantly decreased amount of prostacyclin compared with control rats $(6.5 \pm 2.4$ versus $13.7 \pm 1.7 \mathrm{pmol} / \mathrm{ml}, \quad p<0.05$; Fig. 5). Thus, compartmentalization of substrate and enzyme is not the explanation for the difference in $\mathrm{PGI}_{2}$ production between control and diabetic rat vessels. 


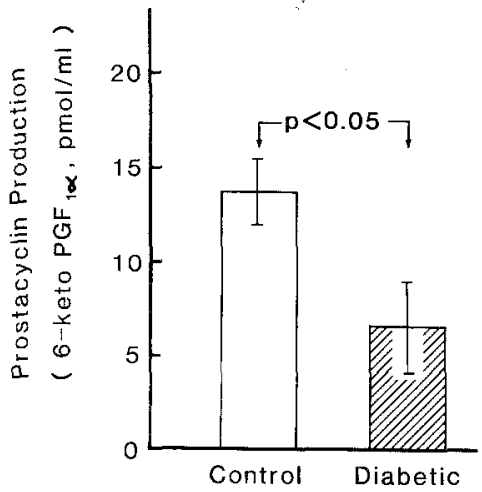

Fig.5. Prostacyclin production by homogenates of rat aorta obtained from control $\square$ and diabetic rats $ש$. Values represent mean \pm SEM for six aortae in each group. Vessels were homogenized after incubation for $10 \mathrm{~min}$ at $37^{\circ} \mathrm{C}$

Table 1. Influence of arachidonate on eicosanoid production in the perfused rat heart

\begin{tabular}{|c|c|c|c|c|}
\hline \multirow[t]{2}{*}{$\begin{array}{l}\text { Dose of } \\
\text { arachidonate }\end{array}$} & \multicolumn{2}{|c|}{$\begin{array}{l}\text { 6 Keto-PGF }{ }_{1 \alpha} \\
(\mathrm{pmol} / \mathrm{ml})\end{array}$} & \multicolumn{2}{|c|}{$\begin{array}{l}\text { Thromboxane } \mathrm{B}_{2} \\
(\mathrm{pmol} / \mathrm{ml})\end{array}$} \\
\hline & Control & Diabetic & Control & Diabetic \\
\hline $30 \mu \mathrm{g}$ & $\begin{array}{r}1.7 \pm 0.4 \\
p\end{array}$ & $\begin{array}{l}4.2 \pm 0.7 \\
0.01\end{array}$ & $\begin{array}{r}0.24 \pm 0.02 \\
N\end{array}$ & $S^{0.25 \pm 0.02}$ \\
\hline $120 \mu \mathrm{g}$ & \multicolumn{2}{|c|}{ NS } & \multicolumn{2}{|c|}{$p<0.02$} \\
\hline
\end{tabular}

All values represent mean \pm SEM for seven to eight values in each group.

Hearts were perfused through the aorta at a constant flow of $14-16 \mathrm{ml} / \mathrm{min}$ with Krebs-Henseleit buffer. Following an initial 15 min equilibration period, arachidonic acid was injected at 15-min intervals into the aortic inflow tract. Coronary effluent was collected for $20 \mathrm{~s}$ following each injection and assayed for 6-keto- $\mathrm{PGF}_{1 \alpha}$ and $\mathrm{TxB}_{2}$ concentration

The effect of diabetes on $\mathrm{PGI}_{2}$ and $\mathrm{TxB}_{2}$ production by perfused hearts is shown in Table 1 . No basal release of either $\mathrm{PGI}_{2}$ or $\mathrm{TxB}_{2}$ could be detected from either control or diabetic hearts. However with the addition of $30 \mu \mathrm{g}$ of arachidonic acid, $\mathrm{PGI}_{2}$ could be detected in coronary effluents. $\mathrm{PGI}_{2}$ release was found to be two to three times higher in hearts of diabetic animals compared with hearts from control rats at this moderate dose of arachidonic acid used. At higher doses of arachidonic acid (i.e $120 \mu \mathrm{g}$ ), there was a significant increase in the concentration of $\mathrm{TxB}_{2}$ generated, but not in that of 6-keto PGF $_{1 \alpha}$ in diabetic hearts. Thus, at high arachidonic acid doses, diabetic hearts shift toward greater thromboxane production than control hearts.

\section{Discussion}

The present studies demonstrate that both the aorta and coronary vessels of diabetic animals show increased responsiveness to prostanoid vasoconstrictors (i. e throm- boxane and endoperoxide analogues). In this connection, aortic rings of diabetic animals showed significantly increased responsiveness to carbocyclic thromboxane $\mathrm{A}_{2}$, a thromboxane analogue, and a tendency towards increased responsiveness to 9,11-methanoepoxy $\mathrm{PGH}_{2}$, an endoperoxide analogue. These findings are consistent with earlier studies on the responsiveness of isolated aortic preparations from diabetic animals, in which an increased responsiveness to non-prostanoid vasoconstrictors, such as noradrenaline, angiotensin, potassium chloride and calcium chloride were reported, $[2,12,18]$ although others have not found this relationship to occur $[14,15,24]$. The explanation for these divergent findings remains unclear. A recent study employing an isolated coronary artery preparation from diabetic dogs found an increased responsiveness to 9,11- methanoepoxy $\mathrm{PGH}_{2}[22,23]$, which is in accordance with the present finding of an increased constrictor response to this endoperoxide analogue in the coronary vessels of isolated perfused hearts from diabetic animals. Since endoperoxides and thromboxanes are thought to exert their constrictor response in vascular smooth muscle by mobilization of external calcium, the increased responsiveness to constrictor agents in vessels isolated from diabetic rats may be associated either with an increased tendency of eicosanoid constrictors to transfer calcium ions inwardly or to a generalized enhanced vascular sensitivity to calcium.

In addition to changes in vascular responsiveness to prostaglandin analogues, alterations were observed in $\mathrm{PGI}_{2}$ formation by aortic and coronary vessels of diabetic rats. In the present study, aortic vessels from diabetic animals showed a decreased release of $\mathrm{PGI}_{2}$ at 5 , 7.5 and 10 min of incubation when compared with control vessels. Furthermore, formation of $\mathrm{PGI}_{2}$ by homogenates of aortic vessels from diabetic animals was reduced, suggesting that the decreased synthesis of $\mathrm{PGI}_{2}$ is not due to a compartmentalization of essential factors in prostacyclin formation within the tissue (e.g. enzymes, substrates, cofactors). These results are in agreement with other studies showing reduced $\mathrm{PGI}_{2}$ release from vessels of diabetic patients and animals [3, $19,20,23]$. The mechanism of the reduced $\mathrm{PGI}_{2}$ release from diabetic vessels is unclear. Possible explanations include: (a) endothelial cell atrophy or damage, (b) decreased prostacyclin synthetase activity, and (c) decreased availability of substrate. In our studies, the addition of exogenous arachidonic acid $(25 \mu \mathrm{mol} / \mathrm{l}) \mathrm{re}-$ sulted in increased prostacyclin release in both diabetic and control rat aortae. In the presence of this exogenous arachidonic acid, there was no difference in prostacyclin release by aortic vessels from diabetic or control animals. These results tend to exclude endothelial cell loss or damage as a major mechanism, and further suggest that inadequate endogenous substrate levels or impaired substrate availability may contribute to reduced prostacyclin release. The fact that high amounts of arachidonic acid enhance prostacyclin production 
further suggests that the biosynthetic pathway responsible for prostacyclin generation can be acutely activated in vessels from diabetic rats. This pathway may be a site of action to consider in future treatment of vascular complications in diabetes.

In contrast to the reduced $\mathrm{PGI}_{2}$ synthesis in aortic tissue, $\mathrm{PGI}_{2}$ release was increased two- to threefold in the isolated perfused heart of diabetic rats. This unusual finding is in agreement with recent reports describing an increased $\mathrm{PGI}_{2}$ release from isolated perfused hearts of acutely diabetic rats [18] and from coronary artery preparations isolated from acutely diabetic dogs [23]. The increased $\mathrm{PGI}_{2}$ formation in diabetic animals may reflect a compensatory action of the coronary vasculature to protect against noxious stimuli. In any event, increased substrate availability has been proposed as a possible mechanism for increased $\mathrm{PGI}_{2}$ production in acutely diabetic animals, since there is a large mobilization and loss of body fat during the first few days following the induction of diabetes [22]. As demonstrated in this study, however, the enhanced $\mathrm{PGI}_{2}$ release is found also in chronically diabetic animals in the presence of exogenous arachidonic acid, which suggests that mechanisms other than increased substrate availability are responsible for the elevated $\mathrm{PGI}_{2}$ production in the coronary vasculature of diabetic animals. The primary mechanism involved remains to be elucidated.

Acknowledgements. We gratefully acknowledge the technical assistance of M. Messenger during the course of these studies. We also thank Dr. K.C. Nicolaou of the University of Pennsylvania, Philadelphia, Pennsylvania, for the generous supply of $\mathrm{CTA}_{2}$; Dr.J.Pike of Upjohn, Kalamazoo, Michigan, for the generous supply of 9,11-methanoepoxy $\mathrm{PGH}_{2}$ (U-46619); and Dr.J. Bryan Smith of The Cardeza Foundation, Thomas Jefferson University, Philadelphia, Pennsylvania, for the thromboxane $\mathrm{B}_{2}$ and 6-keto $\mathrm{PGF}_{1 \alpha}$ antisera. Supported in part by a grant from The Triad Trust of Dr. Ralph and Marion Falk. D. M. Roth is a Fellow of the Ischemia-Shock Research Center. D. K. Reibel is a Postdoctoral Fellow of the National Heart, Lung, and Blood Institute of the National Institutes of Health (HL-06407-01).

\section{References}

1. Carreras LO, Chamone DAF, Klerckx P, Vermylen J (1980) Decreased vascular prostacyclin $\left(\mathrm{PGI}_{2}\right)$ in diabetic rats. Stimulation of $\mathrm{PGI}_{2}$ release in normal and diabetic rats by the antithrombotic compound BAY g 6575. Thromb Res 19: 663-670

2. Czuez R'T, Wenger TL, Kunos G, Szentivany M (1973) Changes of adrenergic reaction pattern in experimental diabetes mellitus. Endocrinology 93: 752-755

3. Gerrard JM, Stuart MJ, Rao GHR, Steffes MW, Mauer SM, Brown DM, White JG (1980) Alteration in the balance of prostaglandin and thromboxane synthesis in diabetes. J Lab Clin Med 95: 950-956

4. Halushka PV, Rogers RC, Loadholt CB, Colwell JA (1981) Increased platelet thromboxane synthesis in diabetes mellitus. J Lab Clin Med 97: 87-96

5. Hamberg M, Svensson J, Samuelsson B (1975) Thromboxanes: a new group of biologically active compounds derived from prostaglandin endoperoxides. Proc Natl Acad Sci USA 72: 2991-2996

6. Harrison HE, Johnson M (1981) Vascular prostacyclin release and metabolic derangement in diabetes. Horm Metab Res [Suppl 11]: 43-49
7. Ingerman-Wojenski C, Silver MJ, Smith JB, Macarak E (1981) Bovine endothelial cells in culture produce thromboxane as well as prostacyclin. J Clin Invest 67: 1292-1296

8. Lagarde M, Burtin M, Berciaud P, Blanc M, Velardo B, Dechavanne $M(1980)$ Increase of platelet thromboxane $A_{2}$ formation and of its plasma half-life in diabetes mellitus. Thromb Res 19: 823-830

9. Lefer AM, Ogletree ML, Smith JB, Silver MJ, Nicolaou KC, Barnette WE, Gasic GP (1978) Prostacyclin: profile of a potentially valuable agent for preserving jeopardized myocardial tissue in acute myocardial ischemia. Science 200:52-54

10. Lewy RI, Wiener L, Walinsky P, Lefer AM, Silver MJ, Smith JB (1981) Thromboxane release during pacing induced angina pectoris: Possible vasoconstrictor influence on the coronary vasculature. Circulation 61: 1165-1171

11. Moncada S, Vane JR (1977) The discovery of prostacyclin (PGX). A fresh insight into arachidonic acid metabolism. In: Kharasch $N$, Fried $\mathbf{J}$ (eds) Interscience prostaglandin symposium, Academic Press, New York, San Francisco, London, pp.155-177

12. Owen MP, Carrier GO (1979) Alteration in vascular smooth muscle sensitivity to vasoconstrictor agents by streptozotocin induced diabetes. Proc West Pharmacol Soc 22: 363-366

13. Palik I, Hadhazy P, Magyar K, Malomvolgyi B, Wagner M, Pogatsa $G$ (1981) Effects of prostaglandins $F_{2 \alpha}, I_{2}$, and indomethacin on isolated coronary arteries from healthy and alloxan-diabetic dogs. Experientia 37: 863-864

14. Pfaffman MA, Hilman R, Darby A (1980) Contractile and relaxing activity of arterial smooth muscle from streptozotocin-diabetic rats. Res Comm Chem Pathol Pharm 30: 283-298

15. Prasad D, Turlapaty MV, Hiim G, Altura BM (1980) Vascular responsiveness and serum biochemical parameters in alloxan diabetes mellitus. Am J Physiol 239: E 412-E421

16. Raabo E, Terkildsen TC (1960) On the enzymatic determination of blood glucose. Scand J Clin Lab Invest 12: 402-406

17. Rogers SP, Larkins RG (1981) Production of 6-oxo-prostaglandin $\mathrm{F}_{1 \alpha}$ by rat aorta. Influence of diabetes, insulin treatment, and caloric deprivation. Diabetes 30:935-939

18. Rosen P, Schrör K (1980) Increased prostacyclin release from perfused hearts of acutely diabetic rats. Diabetologia 18: 391-394

19. Samuelsson B, Goldyne M, Granstrom E, Hamberg M, Hammarstrom S, Malmsten C (1978) Prostaglandins and thromboxanes. Annu Rev Biochem 47:997-1029

20. Schernthaner G, Sinzinger H, Silberbauer K, Freyler H, Muhlhauser I, Kaliman J (1981) Vascular prostacyclin, platelet sensitivity to prostaglandins and platelet specific proteins in diabetes mellitus. Horm Metab Res [Suppl 11]: 33-43

21. Silberbauer K, Clopath P, Sinzinger H, Schernthaner G (1980) Effect of experimentally induced diabetes on swine vascular prostacyclin $\left(\mathrm{PGI}_{2}\right)$ synthesis. Artery $8: 30-36$

22. Sterin-Borda L, Borda ES, Gimeno MF, Hazpari MA, del Castillo E, Gimeno AL (1982) Contractile activity and prostacyclin generation in isolated coronary arteries from diabetic dogs. Diabetologia 22: 56-59

23. Sterin-Borda L, Gimeno M, Borda E, del Castillo E, Gimeno AL (1981) Prostacyclin (PGI) and U-46619 stimulate coronary arteries from diabetic dogs and their action is influenced by inhibitors of prostaglandin biosynthesis. Prostaglandins $22: 267-278$

24. Sullivan S, Sparks HV (1979) Diminished contractile response of aortas of diabetic rabbits. Am J Physiol 236: H 301-H 306

Received: 31 August 1982

and in revised form: 4 January 1983

Dr. Allan M. Lefer

Department of Physiology

Jefferson Medical College

1020 Locust Street

Philadelphia, PA 19107, USA 